\title{
Retraction Note to: Correlations of SELE genetic polymorphisms with risk of coronary heart disease and myocardial infarction: a meta-analysis
}

\author{
Zhao-Qiang Dong ${ }^{1} \cdot$ Xiang-Jun $\mathrm{Wu}^{1} \cdot{\text { Qing-Hua } \mathrm{Lu}^{1}}^{1}$
}

Published online: 18 August 2015

(C) Springer Science+Business Media Dordrecht 2015

\section{Retraction Note to: Mol Biol Rep (2014) 41:3021-3031 \\ DOI 10.1007/s11033-014-3161-2}

The Publisher and Editor retract this article in accordance with the recommendations of the Committee on Publica tion Ethics (COPE). After a thorough investigation we have strong reason to believe that the peer review process was compromised.

The online version of the original article can be found under doi:10. 1007/s11033-014-3161-2.

Qing-Hua Lu

luqinghua1202@126.com

1 Department of Cardiovascular Medicine, the Second Hospital of Shandong University, No. 247 Beiyuan Street, Tianqiao District, Jinan 250033, People's Republic of China 